1981 Particle Accelerator Conference - March 11-13, 1981

\title{
ISABELLE CAVITY GAP ASSEMBLIES
}

M. Plotkin

Brookhaven National Laboratory Upton, New York 11973
BNL-29091

CONF - 810314-.-95

\section{ISABELLE CAVITY GAP ASSEMBLIES}

In a storage ring, where beam lifetime is measured in hours, it is necessary to keep the longitudinal impedance, as seen by the beam, very low, even into the gigahertz region. This is necessary to prevent the excitation of longitudinal instabilities. These impedances are due to the resistive wall effect and any deviation from a smooth vacuum chamber such as at pick-up electrodes, vacuum pump stations, rf cavities, etc. At low frequencies, up to 10 to $20 \mathrm{MHz}$, the low impedance requirement for the cavities can be satisfied by designing the driving power amplifiers with a very low output impedance. For ISABELLE a method has been designed for building a network into the cavity accelerating gaps ${ }^{-}$which will satisfy the impedance criteria to at least $1300 \mathrm{MHz}$.

The maximum allowable impedance at any frequency, $f$, is given in the form $z / n$ where $n=f / f$ rotation. For the ISABELLE accelerating cavity, operating at 235.5 $\mathrm{KHz}, \mathrm{Z} / \mathrm{n}$ must be less than 10 ohms. For the stacking cavity, operating at $4.45 \mathrm{MHz}, \mathrm{z} / \mathrm{n}<1 \mathrm{ohm}$.

\section{Accelerating Gap}

If the accelerating power amplifier provides the required low output impedance below $10 \mathrm{MHz}$, then the network for limiting $\mathrm{Z} / \mathrm{n}$ must perform at frequencies about 40 times the operating frequency of $235.5 \mathrm{KHz}$ (10 $\mathrm{MHz}$ ) and above. An $\mathrm{R}-\mathrm{C}$ network was considered to satisfy the following criteria: 1) the rf current through the resistor at $235.5 \mathrm{MHz}<3$ amps peak, 2) the dissipation in the resistor $\approx 30$ watts max., 3) the addition of any other reactive elements across the network does not create a resonance which exceeds the $\mathrm{Z} / \mathrm{n}$ requirement, 4) the network must present essentially zero series reactance to the beam induced signal.

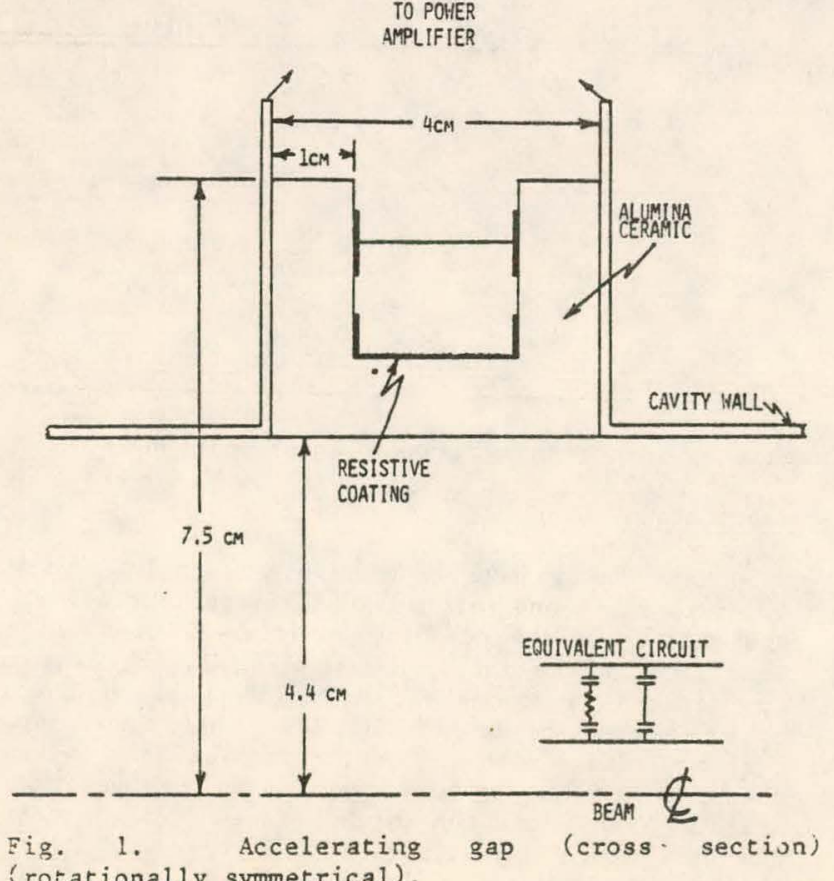

(rotationally symmetrical).

* Work performed under the auspices of the U.S. Dept. of Energy.
Calculations indicated that a simple series $\mathrm{R}-\mathrm{C}$, with $C=50 \mathrm{pf}$ and $R=70 \Omega$, satisfies criteria 1,2 , and 3. Figure 1 shows the gap cross-section which includes this network and also satisfies criterion 4.

Many computer runs were made using an ECAP program for the following network for various values of $z$.

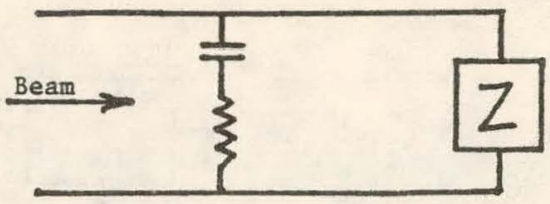

The $2 / n$ criterion was satisfied in all cases for f > $10 \mathrm{MHz}$. A small test cavity was built and measured with an $H-P$ network analyzer, with and without the model gap assembly. Up to $1300 \mathrm{MHz}$, the frequency limit of this network analyzer, the calculations were confirmed.

The gap assembly was then modified by adding a small portion of the cavity tuning capacitance, about $50 \mathrm{pf}$, and additional computer runs were made. The following network was used which includes the cavity elements, leakage inductances and the amplifier output equivalent resistance and capacitance.

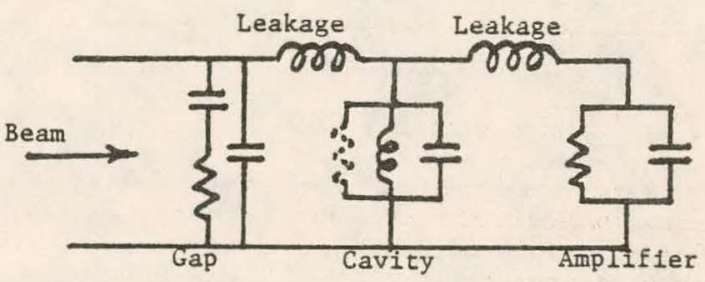

The computer runs were made for different values of leakage inductance and amplifier impedances and, again, the low $z / n$ was obtained. In addition, computer runs were made using different amplifier impedances in different frequency bands and different cavity inductance (due to changes in ferrite permeability) for different frequency bands. Very little change was noted in the impedance as seen by the beam. The amplifier impedance dominated at the low frequencies and the gap network dominated at the higher frequencies. As a final test, a model gap was installed in a full size, ferrite loaded, cavity and tested with the network analyzer. There were some low $Q$ resonances, but in no case did the measured $\mathrm{z} / \mathrm{n}$ exceed the $z / n<10 \Omega$ criterion.

\section{Stacking Gap}

The situation in the stacking gap is more difficult for several reasons. First, if an amplifier can be built to have a low output impedance up to 30 $\mathrm{MHz}$, this is only about seven times the operating frequency of $4.45 \mathrm{MHz}$. For a simple $\mathrm{R}-\mathrm{C}$ the resistor would dissipate very large power. Second, the basic requirement is $z / n<1$ ohm, a factor of ten lower than for the accelerating gap. A modification to the simple $R-C$ was designed using an inductance across the resistor to shunt current around the resistor at the operating frequency but whose impedance at frequencies above $30 \mathrm{MHz}$ would allow the damping 


\section{DISCLAIMER}

This report was prepared as an account of work sponsored by an agency of the United States Government. Neither the United States Government nor any agency Thereof, nor any of their employees, makes any warranty, express or implied, or assumes any legal liability or responsibility for the accuracy, completeness, or usefulness of any information, apparatus, product, or process disclosed, or represents that its use would not infringe privately owned rights. Reference herein to any specific commercial product, process, or service by trade name, trademark, manufacturer, or otherwise does not necessarily constitute or imply its endorsement, recommendation, or favoring by the United States Government or any agency thereof. The views and opinions of authors expressed herein do not necessarily state or reflect those of the United States Government or any agency thereof. 


\section{DISCLAIMER}

Portions of this document may be illegible in electronic image products. Images are produced from the best available original document. 
effect of the resistor to prevail.

Here, as in the accelerating gap, it was possible to select values of $R, L$ and $C$ which satisfied the network criteria, both for the simple gap network alone as well as for the complete network including the leakages and the amplifier. With the component values selected the dissipation in the resistor at the operating frequency of $4.45 \mathrm{MHz}$ is under 30 watts and the rf current through the network is under one ampere peak. Figure 2 shows the comparison of $2 / n$ for the simple $\mathrm{R}-\mathrm{L}-\mathrm{C}$ as calculated and as measured with the network analyzer. At frequencies above those plotted, there is an impedance fall off into the gigahertz range.

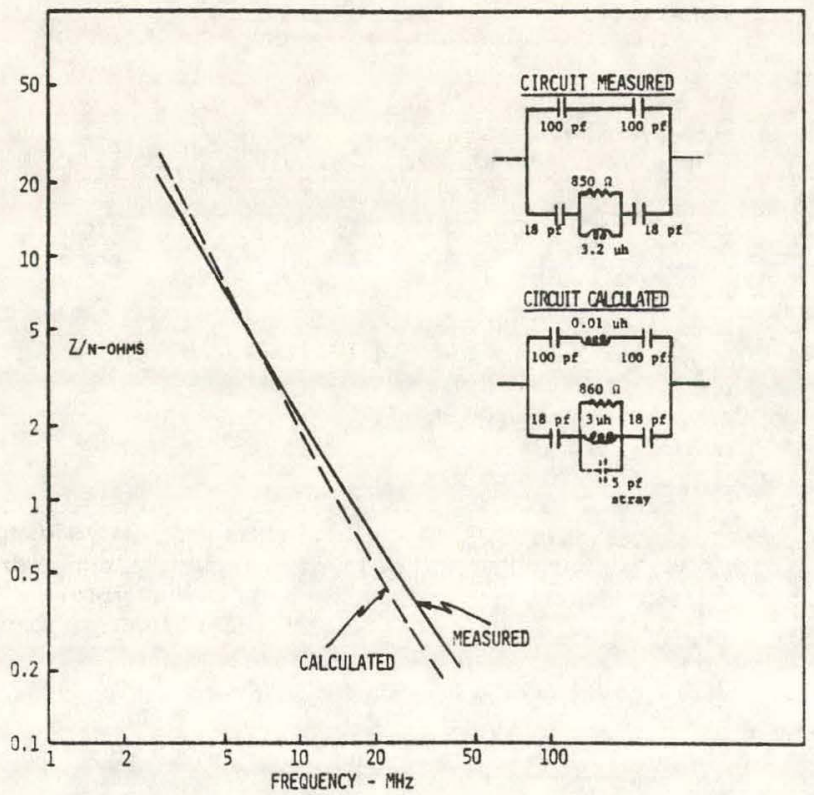

Fig. 2. $\mathrm{Z} / \mathrm{n}$ of stacking gap.

Many computations were made, using ECAP, for various values of components, in the cavity, in the amplifier and of leakage inductances. for all reasonable values, the $2 / n<1$ was maintained. As in the case of the accelerating system, the amplifier impedance determines the input impedance seen by the

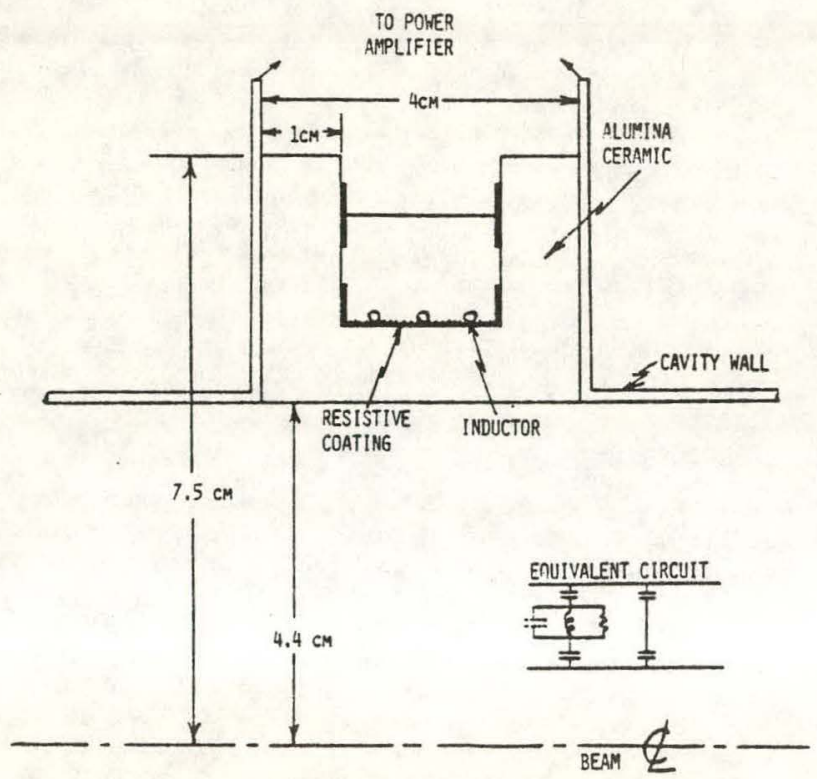

Eig. 3. Stacking gap (cross section). beam at low frequencies and the gap network takes over at higher frequencies.

As in the accelerating gap, there must be an extremely low leakage inductance from the beam induced signal to the damping network. This was accomplished by winding the inductor around the center of the gap as shown in Fig. 3. This is the geometry which performed satisfactorily in the network analyzer test cavity.

A full scale model stacking cavity is being assembled and when it is completed the model gap will be measured again, in place, using the network analyzer.

\section{Gap Shorting}

When the ISA is stacking beam the accelerating cavities must present a $\mathrm{Z} / \mathrm{n}<0.1 \Omega$ to the beam and, conversely, when accelerating the stacking cavity must have a similarly low $\mathrm{Z} / \mathrm{n}<0.1 \Omega$.

Models using $3 / 8^{\prime \prime}$ diameter shorting rods were tested with a single short and with 2,3 and 4 shorts symmetrically displaced around the gap. With a single short, the $z / n<0.1$ was violated, but for 2 or more shorts the criterion was met. The resonance which caused the problem with one short was a circumferential one around the gap.

The proposed construction of the shorting mechanism is to have rods, driven by solenoids or air pistons, cross the gap as required. These shorts will be applied with no voltage present, so there is no sparking problem. (Fig. 4).
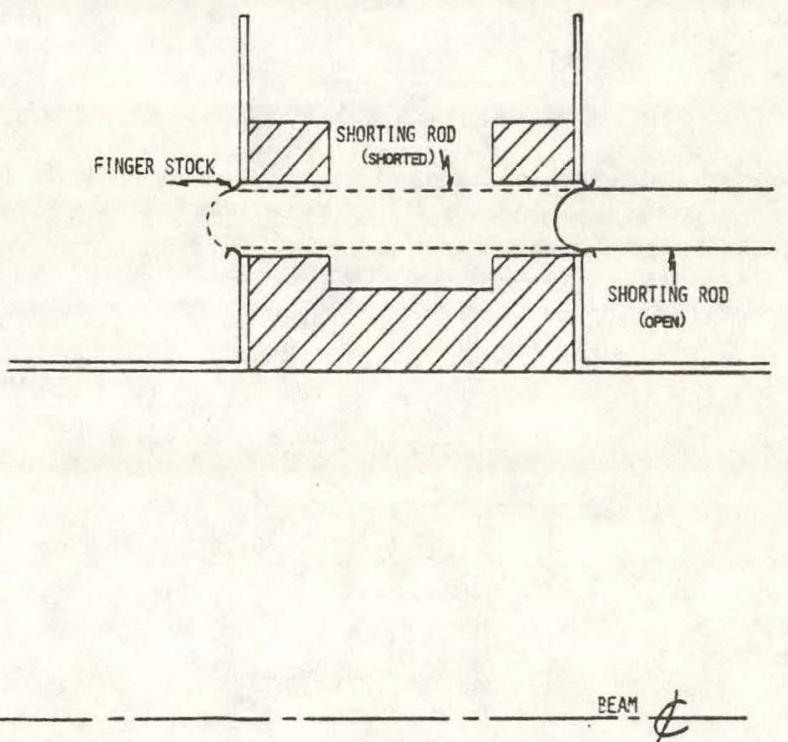

Fig. 4. Shorting mechanism (cross section).

\section{Fabrication}

Many tests have been made on sample pieces in order to solre one particular fabrication problem. If the outside of the ceramic gap is metallized and only a portion on the inside is metallized, then, at high If voltages, a corona streaming takes place from the edge of the inside metallization onto the ceramic surface. Since such a geometry is necessary to create the capacitances in the gap, this problem must be overcome. One solution which has been tested to twice the peak operating voltage of $12 \mathrm{kV}$ is to cover the inside metallization with a clear Dow Corning Sylgard silicone potting material. Other solutions which have 
been tested include an epoxy coating, silicone grease and silicone RTV rubber. Each of these methods has, however, one common problem aside from some obvious disadvantages such as cracking in the epoxy, dirt collection on a silicone grease and possible incomplete coverage using RTV. This problem is the presence of bubbles. Any bubbles will lead to a failure after some period of time. With Sylgard, vacuum pumping to remove moisture and bubbles is part of the curing procedure and the end product is a homogeneous, water clear, material.

The resistance in the gap assembly will be vacuum deposited and, under full load in either cavity, will dissipate less than 0.5 watts/ $\mathrm{cm}^{2}$. Since the gaps will be forced-air cooled by the same system cooling the ferrite, heating will not be a problem.
The metallized surfaces ingide the " $U$ " of the gap will probably be vacuum deposited. The metallized surfaces on the outside of the " $\mathrm{J}$ ", which must maintain $10^{-12}$ Torr in the beam tube, will be fabricated using techniques commensurate with this requirement.

After some additional high voltage and shorting mechanism tests on models, full scale ceramic gap assemblies will be modeled and tested in the model cavities.

Many of the assemblies and tests were made by Phillip Warner who also set up and ran the calculator programs used to reduce the network analyzer data.

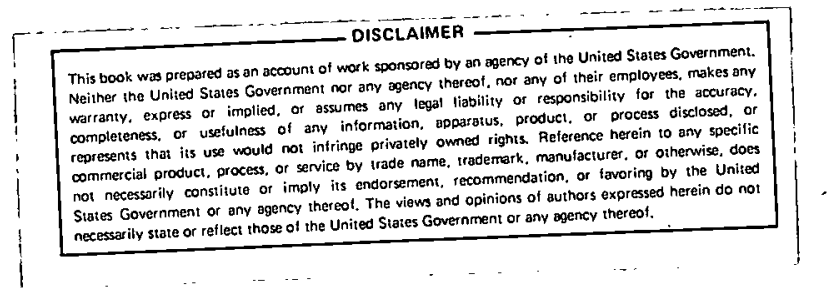

DISTRRALTION OF THIS OOCUMENT IS UNLMMTED 